\title{
A New Approach to Valence and Conduction Band Grading in CIGS Thin Film Solar Cells
}

\author{
Nima E. Gorji, Mauricio D. Perez, Ugo Reggiani, and Leonardo Sandrolini
}

\begin{abstract}
In this paper the characteristics of the graded band gap profiles of CIGS thin film solar cells are reviewed. Influence of the valence and conduction band grading of the absorber material on the main parameters of the cell is considered. A new graded band gap profile which exploits the widening of both the valence and conduction bands is proposed. Furthermore, the possibility of conduction band grading of the window material near the surface region to enhance the carrier transfer is discussed.
\end{abstract}

Index Terms-Band gap grading, CIGS thin film solar cell, performance enhancement, valence band offset.

\section{INTRODUCTION}

$\mathrm{Cu}(\mathrm{In}, \mathrm{Ga})(\mathrm{S}, \mathrm{Se})_{2}$ (CIGS) thin film solar cells have low cost and potentially high efficiency. The record efficiency of about $19.9 \%$ has been achieved in laboratory scale [1]. To improve the device performance, the electronic and optical properties of the cell have to be optimized. Band gap grading of the cell materials is effective on reducing the recombination losses and amplifying the carrier collection in the cell [2-4]. In this paper, we review the characteristics of the last proposed graded band gap profiles and then, due to valence and conduction band widening effects on the performance parameters of the cell, we present a new graded profile in which the band gap widening of the absorber is included both in Conduction Band (CB) and Valence Band (VB). Widening the band edges at the front and back regions of the cell is considered. Furthermore, we discuss the benefit of the $\mathrm{CB}$ grading of the window material near the interface region to enhance the carrier passivation and transfer through the cell.

\section{CONDUCTION BAND GRADING}

In this section, a brief review on the characteristics of the graded profiles is discussed. As early as 1960, Wolf proposed a graded band gap semiconductor for solar cell applications [5]. He showed that the grading of the band gap of the absorber material improves the carrier collection with an increased quasi-drift electrical field in the Space Charge Region (SCR) of the cell. During the last decade, some new graded profiles have also been proposed (Fig. 1) [5].

Manuscript received May 5, 2012; revised August 23, 2012.

The authors are with the Department of Electrical Engineering, Alma Mater Studiorum-University of Bologna, Bologna, Italy (e-mail: nima.eshaghigorji2@unibo.it, ugo.reggiani@unibo.it, leonardo.sandrolini@unibo.it).

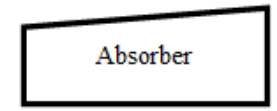

(a)

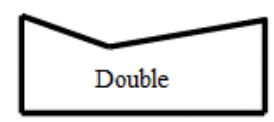

(c)

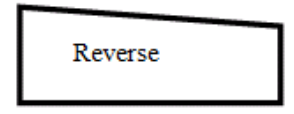

(b)

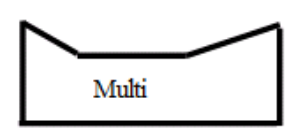

(d)
Fig. 1. CB graded profiles.

Normal Grading: Increasing gradually the Ga content $(0<$ $\mathrm{x}<3)[6]$ in the $\mathrm{Cu}\left(\mathrm{In}_{1-\mathrm{x}}, \mathrm{Ga}_{\mathrm{x}}\right) \mathrm{Se}_{2}$ compound, the band gap of the absorber linearly increases by linearly decreasing the electron affinity through the absorber [7]. In this case, the gradient in the Ga concentration produces a gradient in the electron affinity which is accompanied by a quasi-electrical field through the cell (Fig. 1a). This additional electrical field enlarges the diffusion length of the electrons. Therefore, the carrier collection enhances and helps the minority carriers to be collected. On the other hand, widening the band gap at the back contact of the cell reduces the recombination rate at the metallurgical contact and raises the Open-Circuit Voltage $\left(\mathrm{V}_{\mathrm{OC}}\right)$ of the cell due to a lower recombination current (saturation current) in higher band gap locations. Finally, the small enhancement in efficiency is due to an enhanced carrier collection and a decreased recombination rate. Unfortunately, the Short-Circuit Current Density $\left(\mathrm{J}_{\mathrm{SC}}\right)$ decreases steadily by linearly increasing the band gap as the absorption coefficient depending on position decreases.

Reverse grading: With gradually decreasing the Ga content through the absorber layer, the band gap of the cell is also reduced (Fig. 1b) [8], [9]. With linearly decreasing band gap toward the back contact, the recombination rate at the back contact increases, but in the SCR the electrical quantity $\mathrm{V}_{\mathrm{OC}}$ is high owing to widened band gap and lower recombination rate. In this profile, $\mathrm{J}_{\mathrm{SC}}$ increases steadily due to an increase in the absorption for smaller band gaps, but it is not significant because of a reduced probability of the electron collection affected by a reverse quasi-electrical field [10].

Double grading: In a double graded band gap profile, the efficiency depends on the location of the minimum point of the band gap. In this profile the Ga content decreases from the front surface to an optimum minimum position and then increases to the back contact (Fig. 1c). Both kinds of grading affect the carrier collection probability [11]. Front grading repels minority carriers away from the interface and back grading increases the band gap which enhances the carrier collection by drifting the carriers to the SCR due to an additional electrical field. Therefore, the internal quantum efficiency and position dependent light absorption are 
increased and $\mathrm{J}_{\mathrm{SC}}$ improves. Anyway, the maximum band gap at the back contact has to be optimized in order to obtain an improved short-circuit current density. Without back grading the internal quantum efficiency is lowered owing to the lack of quasi-electrical field which helps the photo-generated carriers to reach the contacts [12]. The optimization of band gap grading in CIGS shows an absolute gain in efficiency up to $3 \%$ [13].

Multi-Grading: Multi-graded band gap structure has showed a better performance than other cases (Fig. 1d). In this case, an improved $\mathrm{V}_{\mathrm{OC}}$ at the front region and an improved $\mathrm{J}_{\mathrm{SC}}$ at the back region are obtained. The cell has been simulated to give an efficiency up to $19.83 \%$ theoretically and $18.8 \%$ experimentally [13]. All above discussed graded band gaps can be obtained by changing the Ga content in the absorber compound. The other possibility to grade the band gap can be grading the VB of the absorber [14]. Some of the authors have also considered the VB grading effects on the cell performance parameters. In Fig. 2, Decock et. al., proposed an absorber with grading towards the SCR with S and grading the back contact with Ga [15]. Grading the absorber material can be conducted by both front $\mathrm{S}$ - and back Ga-grading in the $\mathrm{Cu}\left(\mathrm{In}_{1-\mathrm{x}} \mathrm{Ga}_{\mathrm{x}}\right)\left(\mathrm{Se}_{1-\mathrm{y}}, \mathrm{S}_{\mathrm{y}}\right)_{2}$ solar cells.

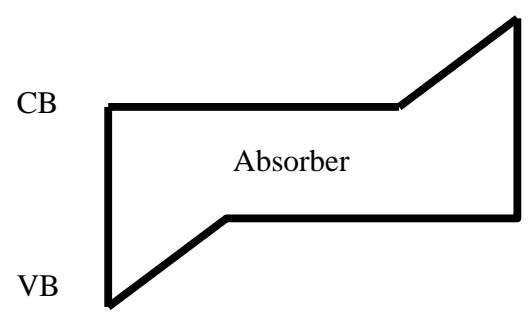

Fig. 2. Grading both valence (front) and conduction (back) bands.

The integration with $\mathrm{S}$ affects both the $\mathrm{CB}$ and VB. The exact distribution between the $\mathrm{CB}$ and VB offset is however complicated and, therefore, they assumed that by S-grading of the surface region the CB stays flat and VB is widened. Also, a Ga graded layer is anticipated for the back region to enlarge the CB only by neglecting the VB offset in the back region. Anyway, in this work small benefit for grading both the front and back regions is attained because grading benefit depends on the perfect control of the defect and doping distributions, appropriate absorber thickness and many other parameters [16]. However, authors are agreeing that with optimization of the cell parameters the graded profile enhances the advantage of the generation and recombination rate in the cell. Finally, the authors assessed grading as successful if it reshapes the generation profile in a way that more charge carriers are generated in regions with less recombination probability.

\section{VALENCE BAND GRADING}

Because of the downward VB shift at the surface region, the band gap of the absorber at the surface region of the cell is at least $0.1 \mathrm{eV}$ greater than that of the bulk region. This shift in the VB can be produced by $\mathrm{Cu}$-poor surface phases (i.e., by $\mathrm{Cu}(\mathrm{In}, \mathrm{Ga})_{3} \mathrm{Se}_{5}$ or by intentional $\mathrm{Ga} / \mathrm{In} / \mathrm{Se} / \mathrm{S}$ grading [17]. In this profile the VB is kept fixed while the conduction band offset increases to widen the band gap. However, many of the papers have stated theoretically and experimentally that the VB offset is effective on the main parameters of the cell, where $\mathrm{V}_{\mathrm{OC}}$ improves by enlarging the barrier high at the surface region by grading the VB at interfaces. For example, Gloeckler and Sites evaluated the effects of the VB widening at a $\mathrm{Cu}$-poor surface and showed that hole depletion at the surface regions by VB offset is the crucial parameter in achieving high $V_{O C}$ at the CdS/CIGS interface [18]. This is due to the hole concentration which is a limiting parameter for recombination rate on the junction surface and can be controlled by the VB grading. When sufficient holes are supplied at the interface, they can limit $V_{O C}$. Analytical findings also verify that the VB position at the interface can limit $V_{O C}$. In another work the same authors considered that the VB offset by $\mathrm{S} / \mathrm{Se}$ alloyed $\mathrm{Cu}$-poor material can increase the barrier high at the interface and lower the recombination rate of the carriers there [19]. They concluded that a large VB offset of $0.4 \mathrm{eV}$ can directly increase the barrier to a sufficiently large value which can eliminate interface recombination. In Fig. 3 we show the effects of the VB offset at the front contact on the cell parameters based on data reported in [20], [21]. The curves prove that the VB widening improves the cell parameters with the exception of $\mathrm{J}_{\mathrm{SC}}$ by reducing the carrier loss and hole depletion at the surface regions. Therefore, based on the above approaches, we present an improved graded profile, considering the valence and conduction band offsets at both sides of the absorber of the cell (Fig. 4).
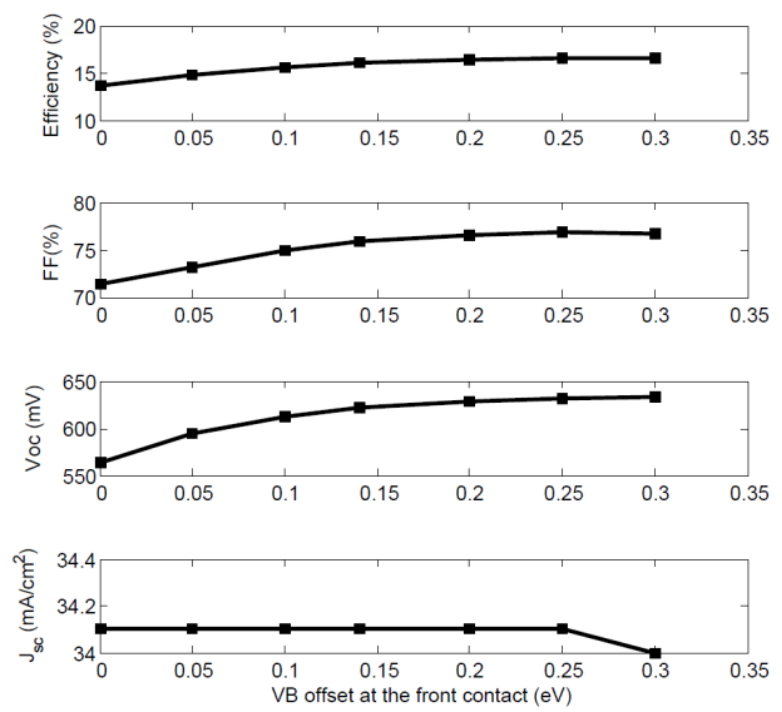

Fig. 3. Effect of the VB offset at the front contact on the cell parameters.

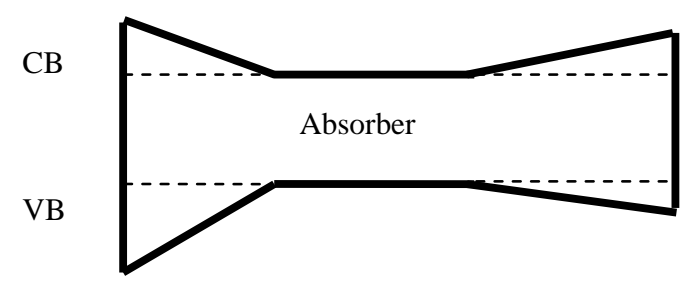

Fig. 4. Graded band gap considering the VB offset.

The last profiles consider just one kind of grading that cannot be close to the real changes during grading the $\mathrm{Ga}$ or $\mathrm{S}$ contents in the absorber. For example, $S$ variations in an absorber of $\mathrm{CuIn}(\mathrm{S}, \mathrm{Se})_{2}$ material influence both the valence 
and conduction bands [22]. However, the exact distribution between the $\mathrm{CB}$ and VB offsets in the different regions of the cell is complicated and should be optimized for the different doping and defect densities. The proposed model is a real one based on the changes in the VB and CB together, which can be produced by doping the absorber with $\mathrm{Ga}$, Se or $\mathrm{S}$ [15], [22]. We suggest that grading lowers the VB edge in both sides of the absorber in Fig. 4; we state that the VB offset at the back contact aids the holes, as majority carriers of the absorber, to reach the contact. For a $\mathrm{CuIn}(\mathrm{S}, \mathrm{Se})_{2}$ absorber material a suitable improvement in $\mathrm{V}_{\mathrm{OC}}$ can be obtained by an appropriate doping concentration of $\mathrm{S}$ or Se. Moreover, a S-rich surface and a Se-rich back region can provide a good overlap between the band gap of the absorber and solar spectrum (1.5 and $1.1 \mathrm{eV}$, respectively). It should be noticed that by doping the absorber material the VB offset becomes greater than that of the CB [23]. At the back surface, grading the band gap with $\mathrm{S}$ leads to a widening of both the VB and $\mathrm{CB}$ with a larger value of the VB offset. The performance of this profile is enhanced because of the advantages of the offsets in the junction regions. The VB widening at the surface region has a main effect on the performance parameters of the cell. The VB offset reduces the saturation current at the surfaces which is accompanied with a hole depletion by the barrier height enlarging and hole passivation enhancement. On the other hand, the CB produces a quasi-electrical field which repels the electrons from the surface region. At the back region the $\mathrm{CB}$ offset assists the minority carriers to be collected and contribute to the current. However, this profile seems to be closer to reality as a graded absorber profile where both the CB and VB offsets have been considered. For example, inserting the defects in the front and back surfaces leads to the offset in both the band edges which shapes the proposed profile in Fig. 4 [24].

\section{WINDOW GRADING}

One of the effective factors on the performance of the CIGS solar cells is the CB offset between the window layer and absorber layer at the interface. Recent calculations of the electron affinity difference between the window and absorber layers showed that the $\mathrm{CB}$ minimum of the absorber is below that of the window. In this state, a spike occurs in the $\mathrm{CB}$ at the interface which is accompanied with a widening of the window CB. Further considerations have shown that this spike can improve $\mathrm{V}_{\mathrm{OC}}$ of the cell due to a lowering of the recombination of the electrons of the window and holes of the absorber at the interface [25]. The CB offset between the window and absorber can be also a cliff which reduces the efficiency owing to the increase of the recombination current at the interface. For the case of spike, however, a lower $\mathrm{J}_{\mathrm{SC}}$ is obtained which is due to the barrier against transferring the photo-generated electrons from the absorber to the window, anyway, the existence of a suitable spike in the interface increases the barrier against the injected electrons at the interface and, therefore, decreases the entire buck current density and enhances $\mathrm{V}_{\mathrm{OC}}$ of the cell. We propose the grading of the $\mathrm{CB}$ of the window at the surface region to enhance the carrier transferring ability. Slightly increasing the $\mathrm{CB}$ towards the interface of the window results in a gradient in electron affinity and conducts the electrons to leave the interface which increases both the filling factor and conversion efficiency. In this way, the photocurrent is enhanced. This grading can be obtained by n-doping of the window material. For example, by n-doping of the $\mathrm{CdS}$ window of a CdS/CIGS solar cell [26] or variation of the $\mathrm{Mg}$ content at the surface region of the window of a $\mathrm{ZnMgO/CdS/CIGS} \mathrm{cell} \mathrm{[27].}$

\section{CONCLUSION}

In summary, we consider the characteristics of the available graded band gap profiles of the CIGS solar cells. We propose and discuss the possibility and advantages of a new improved graded profile where both the valence and conduction bands are considered at both sides of the absorber. At the front region of this profile, the VB widening enlarges the hole depletion as a limiting factor for $\mathrm{V}_{\mathrm{OC}}$, the $\mathrm{CB}$ grading reduces the recombination rate of the carriers at the interface. At the back region, the VB grading enhances the transfer ability of the majority carriers and the $\mathrm{CB}$ grading improves collection probability of the carriers to contribute to the current. However, this profile can better define the grading changes on the valence and conduction bands, i.e., for a $\mathrm{S}$-graded absorber material. We also discuss the possibility of grading the front region of the window layer to enhance the passivation and transfer of the electrons coming from the absorber.

\section{REFERENCES}

[1] I. Repins, M. A. Contreras, B. Egaas, C. Dehart, J. Scharf, C. L. Perkins, B. To, and R. Noufi, "19.9\%-efficient $\mathrm{ZnO} / \mathrm{CdS} / \mathrm{CuInGaSe} \mathrm{C}_{2}$ solar cell with $81.2 \%$ fill factor,” Prog. Photovolt. vol. 16, pp. 235-239, Feb. 2008.

[2] R. Menner, T. Walter, and H. W. Schock, "Photocurrent transport in heterojunctions with graded $\mathrm{Cu}$ (In, Ga) Se absorbers," in Proc. 10th Photovoltaic Solar Energy Conf., 1991, pp. 787-792.

[3] M. A. Contreras, J. Tuttle, A. Gabor, A. Tennant, K. Ramana, S. Asher, A. Franz, J. Keane, L. Wang, and R. Nouf, "High efficiency graded band gap thin-film polycrystalline $\mathrm{Cu}$ (In, Ga) Se -based solar cells,' Solar Energy Materials and Solar Cells, vol. 41/42, pp. 231-236, Dec. 1996.

[4] A. M. Gabor, J. R. Tuttle, M. H. Bode, A. Franz, A. L. Tennant, M. A. Contreras, R. Noufi, D. G. Jensen, and A. M. Hermann "Band gap engineering in $\mathrm{Cu}$ (In, Ga) Se thin films grown from (In, Ga) Se precursors," Solar Energy Materials and Solar Cells, vol. 41/42, pp. 247-250, Jan. 1996.

[5] M. Wolf, "Limitations and possibilities for improvement of photovoltaic solar energy converters; Part I: Considerations for earth's surface operation," in Proc. IRE., 1960, pp. 1246-1263.

[6] D. Schmid, M. Ruckh, F. Grunwald, and H. W. Schock, "Chalcopyrite/defect chalcopyrite heterojunctions on the basis of CulnSe 2 ," J. Appl. Phys., vol. 73, 6, pp. 2902-2909, Dec. 1992.

[7] J. Mattheis, P. J. Rostan, U. Rau, and J. H. Werner, "Carrier collection in $\mathrm{Cu}(\mathrm{In}, \mathrm{Ga}) \mathrm{Se}_{2}$ solar cells with graded band gaps and transparent ZnO:Al back contacts," Solar Energy Materials and Solar Cells, vol. 91, pp. 689-695, Dec. 2007.

[8] A. M. Acevedo, "A Simple model of graded band gap Cu (In, Ga) $\mathrm{Se}_{2}$ solar cells," E-MRS Spring meeting 2009, Symposium B, Energy Procedia 2, pp. 169-176, Dec. 2010.

[9] A. M. Acevedo, "Effective absorption coefficient for graded band gap semiconductors and the expected photocurrent density in solar cells," Solar Energy Materials and Solar Cells, vol. 93, pp. 41-44, Feb. 2009.

[10] S. K. Chattopadhyaya and V. K. Mathur, "Carrier distribution in graded band gap semiconductors under asymmetric band edge gradients," Phys. Rev. B vol. 9, no. 8, pp. 3517-3523, April 1974. 
[11] M. Topic, F. Smole, and J. Furlan, "Band gap engineering in $\mathrm{CdS} / \mathrm{Cu}$ (In, Ga) $\mathrm{Se}_{2}$ solar cells," J. Appl. Phys., vol. 79, 11, pp. 8537-8540, May 1996.

[12] M. Troviano and K.Taretto, "Analysis of internal quantum efficiency in double-graded band gap solar cells, including sub band gap absorption," Solar Energy Materials and Solar Cells, vol. 95, pp. 821-828, Feb. 2011.

[13] J. Song, S. S. Li, C. H. Huang, O. D. Crisalle, and T. J. Anderson, "Device modeling and simulation of the performance of $\mathrm{Cu}\left(\mathrm{In}_{1-\mathrm{x}}, \mathrm{Ga}_{\mathrm{x}}\right) \mathrm{Se}_{2}$ solar cells," Solid State Electronics, vol. 48, pp. 73-79, July 2004.

[14] T. Dullweber, O. Lundberg, J. Malmstr, M. Bodegard, L. Stolt, U. Rau, H. W. Schock, and J. H. Werner, "Back surface band gap gradings in $\mathrm{Cu}(\mathrm{In}, \mathrm{Ga}) \mathrm{Se}_{2}$ solar cells," Thin Solid Films, vol. 387 pp. 11-13, June 2001.

[15] K. Decock, J. Lauwaerta, and M. Burgelmana, "Characterization of graded CIGS solar cells," E-MRS Spring Meeting 2009, symposium B, Energy Procedia 2, pp. 49-54, Dec. 2010.

[16] M. Turcu, I. M. Kotschau, and U. Rau, "Composition dependence of defect energies and band alignments in the $\mathrm{Cu}$ (In, Ga) $(\mathrm{Se}, \mathrm{S})_{2}$ alloy system," Apply. Phys. Lett, vol. 91, no. 3, pp. 1391- 1399, Feb. 2002.

[17] M. L. C. Cooray and V. G. Karpov, "Physical Model of CdS-Based Thin Film Photovoltaic Modules," Appl. Phys. Letters, vol. 88, pp. 1391-1399, Feb. 2006.

[18] M. Gloeckler and J. R. Sites, "Efficiency limitations for wide band gap chalcopyrite solar cells," Thin Solid Films, vol. 480, pp. 241-245, Dec. 2005.

[19] M. Turcu, O. Pakma, and U. Rau, "Interdependence of absorber composition and recombination mechanism in $\mathrm{Cu}$. (In, Ga) (Se, S) heterojunction solar cells," Appl. Phys. Lett. vol. 80, no. 14, pp. 2598-2600, Feb. 2002.

[20] C. H. Huang, "Effects of junction parameters on $\mathrm{Cu}$ (In, Ga) $\mathrm{Se}_{2}$ solar cells," J. Phys. and Chem. Solids, vol. 69, pp. 779-783, June 2008.

[21] C. H. Huang, "Effects of Ga content on $\mathrm{Cu}$ (In, Ga) Se 2 solar cells studied by numerical modeling," J. Phys. \& Chem. Solids, vol. 69, pp. 330-334, June 2008.

[22] S. H. Wei, S. B. Z.hang, and A. Zunger, "Effects of Ga addition to $\mathrm{CuInSe}_{2}$ on its electronic, structural, and defect properties," Appl. Phys. Lett. vol. 72, no. 24, pp. 3199-3201, June 1998.

[23] T. Dullweber, U. Rau, M. A. Contreras, R. Noufi, and H. W. Schock, "Photogeneration and carrier recombination in graded gap $\mathrm{Cu}$ (In, Ga) $\mathrm{Se}_{2}$ Solar Cells," IEEE Trans. Electron Devices, vol. 47, no. 12, pp. 2249-2254, Dec. 2000

[24] V. Izquierdo-Roca, X. Fontané, J. Á. Garcia, L. C. Barrio, A. P. Rodríguez, J. R. Morante, C. M. Ruiz, E. Saucedo, and V. Bermúdez, "Electrochemical synthesis of $\mathrm{Cu}$ In $(\mathrm{S}, \mathrm{Se})_{2}$ alloys with graded composition for high efficiency solar cells," Apply. Phys. Lett., vol. 94, pp. 061915-1- 061915-3, Feb. 2009.

[25] S. B. Zhang, S. H. Wei, and A. Zunger, "Defect physics of the CuInSe chalcopyrite semiconductor," Phys. Rev. B, vol. 57, no. 16, pp. 96429656, Apr. 1998.

[26] A. Niemegeers, M. Burgelman, and A. De. Vos, "On the CdS/CuInSe conduction band discontinuity," Apply. Phys. Lett., vol. 67 no. 6, pp. 843-845, Aug. 1995.

[27] T. Minemoto, T. Matsui, H. Takakura, Y. Hamakawa, T. Negami, Y. Hashimoto, T. Uenoyama, and M. Kitagawa, "Theoretical analysis of the electron of conduction band offset of window/CIS layers on performance of CIGS solar cells using device simulation," Solar Energy Materials and Solar Cells, vol. 67, pp. 83-88, 2001.

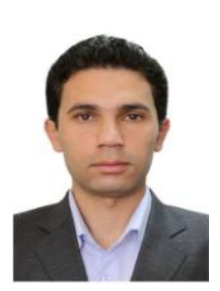

N. E. Gorji was born in north of Iran, on 10 May, 1984. He received the B.Sc. and M.Sc. degree in Physics of Optics and Laser from the University of Tabriz, Iran, in 2008 and 2010, respectively. He won a prize for his master thesis on Quantum Dot Solar Cells by the Iranian Nanotechnology Initiative Council. From 2006 he has the support of the Presidential and National Foundation of Elites. He is currently a Ph.D. student in Electrical Engineering (Photovoltaic Systems) at the University of Bologna, Bologna, Italy. His research interests are physics and characterization of nanostructure quantum confined solar cells and thin film solar cells and modules.

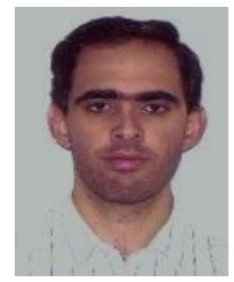

M. D. Perez was born in Buenos Aires, Argentina, on 25 July, 1980. He received the Argentinean B.Sc. degree in Electronic Engineering from the National Technological University, Mendoza Regional, Argentina, in 2007. He recently obtained the Ph.D. in Electrical Engineering at the University of Bologna, Bologna, Italy. His research interests are electromagnetic compatibility, electromagnetic characterization of dispersive materials.

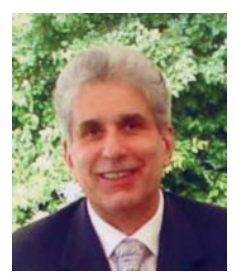

U. Reggiani received the Laurea degree (with honors) in Electrical Engineering from the University of Bologna, Bologna, (Italy), in 1969. He was appointed Assistant at the Faculty of Engineering, University of Bologna, in 1971, Assistant Professor in 1976, and Full Professor of Electrotechnics in 1980. He was Head at the same University of both the Institute of Electrotechnics from 1989 to 1995 , and the Department of Electrical Engineering from 1995 to 2001. He was coordinator of the Doctorate in Electrical Engineering from 1988 to 1998. Since 2002 he is Chairman of the Board of professors of the Electrical Engineering Courses. He was also Adjunct Professor at the University of Modena and Reggio Emilia, Modena, Italy, from 1990 to 2009. His main research interests concern electromagnetic field theory, analytical and numerical methods for the analysis and synthesis of electromagnetic and electromechanical devices, analysis of switched networks, high-frequency modeling of wound components, and currently electrical characterization of renewable energy sources and electromagnetic compatibility. He is co-Author or Author of more than 100 papers.

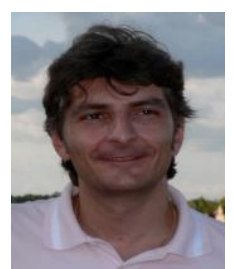

L. Sandrolini received the Laurea degree (cum laude) in 1995 and the Ph.D. degree in 2000, both in Electrical Engineering, from the University of Bologna, Bologna, Italy. Since 2001, he is with the Department of Electrical Engineering, University of Bologna, as a Tenured Researcher and Assistant Professor. He currently lectures Electromagnetic Compatibility at the University of Bologna. He was also Adjunct Professor at the University of Modena and Reggio Emilia, Modena, Italy, from 2002 to 2010. His research interests are in the areas of electromagnetic field theory, electromagnetic compatibility (shielding, electromagnetic coupling, electromagnetic characterization of dispersive materials, electromagnetic interference in switching converters) and electrical characterization of renewable energy sources. He is a reviewer for the IEEE Transactions on Electromagnetic Compatibility and on Industrial Electronics, Compel, Journal of Electromagnetic Waves and Applications, PIER Journal, Elsevier Renewable Energy, MDPI Energies. 